\title{
Configurações
}

Revista de sociologia

Dinâmicas globais e arranjos produtivos para agricultura familiar: o caso do polo de fruticultura Juazeiro-Petrolina no território do Vale do Submédio do Rio São Francisco, Região Nordeste do Brasil

Dynamic global production and arrangements for family farm: the case of fruit polo Juazeiro-Petrolina in the territory of the Valley of the São Francisco River Lower Basin, north eastern Brazil Production mondiale dynamique et organisation de la ferme de la famille: le cas des fruits polo Juazeiro-Petrolina sur le territoire de la Vallée du fleuve São Francisco bassin inférieur, le nord du Brésil

\section{Celso Franca}

\section{OpenEdition}

Journals

\section{Edição electrónica}

URL: http://journals.openedition.org/configuracoes/1898

DOI: $10.4000 /$ configuracoes. 1898

ISSN: $2182-7419$

\section{Editora}

Centro de Investigação em Ciências Sociais

\section{Edição impressa}

Data de publição: 1 Junho 2013

Paginação: 43-59

ISBN: 1646-5075

ISSN: 1646-5075

\section{Refêrencia eletrónica}

Celso Franca, «Dinâmicas globais e arranjos produtivos para agricultura familiar: o caso do polo de fruticultura Juazeiro-Petrolina no território do Vale do Submédio do Rio São Francisco, Região Nordeste do Brasil », Configurações [Online], 11 | 2013, posto online no dia 22 setembro 2014, consultado o 20 abril 2019. URL : http://journals.openedition.org/configuracoes/1898; DOI : 10.4000/ configuracoes. 1898

Este documento foi criado de forma automática no dia 20 Abril 2019. 


\section{Dinâmicas globais e arranjos produtivos para agricultura familiar: o caso do polo de fruticultura Juazeiro-Petrolina no território do Vale do Submédio do Rio São Francisco, Região Nordeste do Brasil}

Dynamic global production and arrangements for family farm: the case of fruit polo Juazeiro-Petrolina in the territory of the Valley of the São Francisco River Lower Basin, north eastern Brazil Production mondiale dynamique et organisation de la ferme de la famille: le cas des fruits polo Juazeiro-Petrolina sur le territoire de la Vallée du fleuve São Francisco bassin inférieur, le nord du Brésil

\section{Celso Franca}

\section{Introdução: o problema}

1 Neste artigo pretende-se analisar o processo de inserção da agricultura familiar no contexto das dinâmicas globais, tendo para tal selecionado como estudo de caso o polo da fruticultura d Juazeiro e Petrolina localizado no Submédio de São Francisco com uma população de 492065 habitantes. A sua atividade econômica está centrada na agricultura irrigada e possui uma infra-estrutura de comercialização e serviços. Entre as indústrias instaladas na região, destacam-se processadoras agrícolas, implementos agrícolas e equipamentos de irrigação. $O$ polo oferece atrativos, como a disponibilidade de terra e 
água do Rio São Francisco: uma infra-estrutura de irrigação implantada e em expansão; uma relativa proximidade dos mercados europeu e norte-americano; um ciclo produtivo mais precoce e altos níveis de produtividade. O polo ainda apresenta mais de cem mil hectares e um potencial superior a duzentos e vinte mil hectares.

2 O processo de incorporação da agricultura familiar no capitalismo, embora tenha conhecido uma longa evolução desde meados do século XIX, conheceu um maior impulso a partir de fi nais daquele século e princípios do século XX nos países capitalistas avançados, com repercussões noutros países dependentes e (semi)periféricos, numa relação de troca desigual conforme as teses defendidas pela Cepal - Comissão Econômica para a América Latina e o Caribe. Será, porém, no período do pós II Guerra Mundial que a aplicação da ciência e da tecnologia nas sociedades agrárias vai representar um processo de modernização e introdução de novos inputs em maquinaria e fertilizantes, aumentando a produtividade das pessoas ativas na agricultura, criando a expectativa da resolução de problemas de carência alimentar com menor taxa de população ativa na agricultura, libertando cada vez mais força de trabalho para os setores secundário e terciário.

3 Neste período do pós-guerra e, particularmente, após os anos setenta e oitenta do século XX, o capitalismo mundial corporizou uma forte transformação na base da utilização das novas tecnologias de mecanização e automação produtiva. Do ponto de vista da doutrina econômica, emerge o chamado modelo teórico neoliberal, inicialmente patrocinado por Hayek (1990) e discutido no Brasil através do seu livro O Caminho da Servidão, o qual viria a contribuir para a crescente difusão da formulação de um Estado mínimo, não intervencionista, numa sociedade baseada na livre iniciativa, na concorrência e na liberdade. Politicamente, foram os governos de Reagan e Margaret Thatcher, na década de 1980, respectivamente nos Estados Unidos e na Inglaterra, que materializaram as ideias e expandiram tais doutrinas. No quadro de crescimento econômico, as novas tecnologias, principalmente as fundamentadas na microinformática, promoveram grandes avanços de produtividade. No final dos anos oitenta, vários estudiosos, com destaque para Piore e Sabel (1984), passaram a discutir de modo mais incisivo essas transformações que se processaram na economia em todo o mundo: as mudanças nas empresas, que passaram a operar com novas tecnologias, e o aumento da produtividade, resultando em alterações organizacionais e na flexibilização do trabalho na busca de maior intensificação da competitividade.

Deste modo, romperam-se fronteiras em prol do crescimento, alegadamente em prol dos povos, com base na autorregulação do mercado e sob um discurso de cunho alegadamente progressista, com promessas de abundância de bens para todos e de fomento da união entre as nações. Todavia, a realidade empírica evidencia outra face deste processo: seletividade, polarização, desigualdade, exclusão social são apenas algumas das consequências perceptíveis deste processo que apenas em parte conseguiu realizar as promessas originariamente concebidas.

5 Também o Brasil, embora um pouco mais tardiamente, buscou na modernização tecnológica alcançar o nível de desenvolvimento necessário para a sua inserção nos mercados mundiais. A racionalização do processo produtivo e da organização social e técnica do trabalho teve como meta principal acelerar o aumento da produtividade e ampliar as condiçães de produção de excedentes, o que foi potenciado pela intensificação da globalização mundial. 
6 Os territórios rurais no Brasil não ficaram por certo imunes à lógica da globalização. Eles aparecem revestidos de novas características e, nesse novo contexto, o espaço agrário está tecido e emaranhado pela atuação das empresas e dos conglomerados. Tal não se deu por acaso, uma vez que o espaço agrário está inserido dentro de um contexto do chamado desenvolvimento agrícola que, a nível produtivo, envolve um conjunto de mudanças no uso do solo (utilização de máquinas, fertilizantes químicos), orientando e marcando fortemente nas últimas décadas as atividades agroindustriais.

7 Diante do exposto, pretende-se discutir, a partir deste estudo, os impactos das dinâmicas globais para a agricultura familiar ${ }^{1}$, oriundos dos novos modelos organizativos no polo da fruticultura de Juazeiro-Petrolina (SMSF) ${ }^{2}$.

8 As análises que se seguem têm por objetivo penetrar nas diversas dimensões que compõem a agricultura familiar na busca de respostas com as seguintes indagações: Quais as razões deste processo e quais os impactos causados a partir da reestruturação agrícola na região do Submédio Rio São Francisco? Em que medida as políticas públicas implantadas através do Estado nessa região fortaleceu ou não os agricultores familiares?

Levando-se em conta o problema delineado acima, partiu-se das seguintes hipóteses: A agricultura familiar foi um segmento historicamente "negado" no quadro do "desenvolvimento" econômico do Nordeste brasileiro. A dinâmica da agricultura no polo de Juazeiro/Petrolina decorreu basicamente da capacidade que os grandes produtores tiveram de se apropriar de uma estrutura com incentivos do Estado, inicialmente planejada para atender o pequeno produtor regional.

Os agricultores familiares foram submetidos e forçados a se adaptar aos novos modelos organizativos de produção, mas nem todos o conseguiram de modo adequado e vantajoso. Enquanto uns poucos conseguiram responder favoravelmente ao referido padrão tecnológico, a maioria navega à deriva num ambiente amplamente mutante e competitivo sem perspectiva de tirar proveito da reestruturação tecnológica e produtiva.

\section{Breve abordagem teórica e metodologia na coleta de dados}

11 Os impactos da globalização no Submédio São Francisco obrigam a adotar um enfoque multidimensional em razão da sua complexidade política e econômica. A perspectiva liberal pluralista (Dahl, 1989) parte do pressuposto de que os atores sociais, não só individuais como de grupos de interesse, são livres e têm a capacidade, em termos competitivos, de influenciar o processo de tomada de decisões, posicionamento que viria a ser objeto de crítica por vários autores, entre os quais Silva (2005), uma vez que nem todos os atores detêm o mesmo grau de recursos de ordem não só econômica como política.

12 Torna-se assim necessário analisar os problemas agrários e as política promovidas pelo Estado, tendo em conta não só a sua complexidade como o cruzamento de interesses e estratégias dos diversos atores em presença, o que implica considerar as diferentes respostas e apreciações em torno da implementação das políticas estatais. Por outro lado, importa avaliar as formas particulares de intervenção do Estado (Fonte, 2000: 33), a nível local e nacional e examinar como a política é transformada durante o processo de implementação, tendo por base a valorização dos estudos de caso na análise dos impactos sociais. 

o pesquisador focaliza os fenômenos sociais concretos, em que os diferentes paradigmas são revelados. A grande maioria dos agricultores familiares cabe na definição do camponês e da casa camponesa, tal como o teorizou Chayanov (1981): "uma unidade de produção e consumo, na qual os membros da família fazem o trabalho e a administração do estabelecimento produtivo." Nesta distinção a partir da finalidade da pequena produção, o pequeno produtor não tem como objetivo o lucro, mas a reprodução da família e, para assegurar isto, se dispõe a produzir, isto é, a continuar trabalhando por uma remuneração muito baixa. conhecimento, seja no plano compreensivo, centrado na ação ou jogo das significações que os atores conferem às suas práticas, seja no plano explicativo, visando estabelecer os fatores e variáveis que condicionam um fenômeno social. Tais instrumentos renovam os procedimentos e as operações para os quais os dados empíricos ou fontes de evidências são recolhidos e analisados. abordar uma sequência histórica e um espaço geográfico mais amplo. Neste caso, particularmente no Submédio São Francisco, temos presente cerca de quarenta anos de transformações econômicas, sociais, culturais e ambientais significativas.

16 A abordagem empírica é tomada como estudo de caso, o Projeto de Irrigação - Maria Teresa, localizado em Petrolina-PE, ocupado por 540 pequenos agricultores familiares, o qual entrou em operação em 1996. Para a coleta de informações sobre a implementação de políticas públicas adotadas nesse Projeto de irrigação, foi selecionada, dentre este universo, uma amostra de 54 agricultores familiares, em que foi possível identificar a situação socioeconômica, fatores de produção, tipo de cultura plantada, colheita, extensão rural e comercialização do produto.

Cabe aqui um esclarecimento sobre a questão de ser significativo pesquisar o Projeto Maria Teresa. No caso da agricultura familiar no polo de Juazeiro/ Petrolina, os projetos apontam para uma classificação genérica, ou seja, os pequenos produtores foram distribuídos em áreas irrigadas que variam entre três e oito hectares. Nessas áreas é comum a utilização de ferramentas básicas e operações unitárias básicas no plantio, com trabalhos de regimes assemelhados. Note-se que ao se dizer assemelhados não se quer dizer idênticos.

Assim, este Projeto, pelo seu porte de produção e quantidade de pequenos produtores ali instalados, torna-se significativo pesquisar, na medida em que, partindo dele, se pode inferir algo que se passa noutros projetos de irrigação do polo de Juazeiro/Petrolina, prestando-se como contraprova para outras pesquisas.

19 A opção por um estudo de caso justifica-se pelo fato de possibilitar a coleta de evidências por meio de diferentes fontes, entre as quais se destacam entrevistas, observações diretas, além da pesquisa bibliográfica. No nosso plano de coleta de evidências foram utilizadas essas fontes, por vezes concomitantemente, por vezes de forma isolada.

20 Quanto às entrevistas, elas foram levadas a cabo de duas formas. A primeira foi semidirectiva, dada a possibilidade de o informante-chave se tornar intérprete dos fatos estudados na medida em que tece considerações sobre determinados acontecimentos e sugere outros informantes que podem acrescentar novos dados à pesquisa. Tal procedimento coloca o entrevistado no papel de um verdadeiro "informante" e não de um 
mero "respondente". Esse tipo de entrevista aconteceu em momentos de eventos (festas, eventos religiosos, reuniões informais), principalmente com alguns agricultores avessos a responder ao questionário em termos formais, mas dando informações sobre alguns pontos do guião de entrevistas.

O segundo tipo de entrevista tem por base um questionário com perguntas de ordem qualitativa e quantitativa, realizado com agricultores mais qualificados (técnicos agrícolas), que serviram para aprofundar as questões já conhecidas, oriundas das entrevistas espontâneas. Foram realizadas 54 entrevistas, as quais representam $10 \%$ do universo dos agricultores ali assentados, incluindo as entrevistas espontâneas.

Seguindo as orientações de Yin (2005: 126), ao se utilizar múltiplas fontes de evidências, criam-se "estratégias hibridas" ou uma triangulação de dados. A vantagem mais importante no uso de fontes múltiplas de evidências é o desenvolvimento de linhas convergentes de investigação. Nesse caso, tem-se a consciência de que o "olhar", o "escutar" e o "escrever" (Cardoso, 2000: 18) sobre pessoas e espaços sociais dinâmicos é considerar a complexidade dos fenômenos e as singularidades, tentando, como refere Geertz (2000: 227), "navegar no paradoxo plural/unificado, produto/processo", dando atenção tanto a assuntos complexos quanto aos mais simples.

\section{A reestruturação produtiva do capitalismo no Brasil: antecedentes históricos}

23 No início dos anos sessenta do século passado, o debate em torno da questão agrária no Brasil foi marcado por posições divergentes. A estratégia de desenvolvimento a ser adotada para solucionar os problemas enfrentados no meio rural era a de que a agricultura brasileira apresentava uma baixa produtividade, gerando em função disto (Oliveira, 1987: 136) crises no abastecimento interno e, consequentemente, elevação nos preços dos produtos agrícolas. Por outro lado, a contribuição da agricultura para a exportação era pequena, representando assim uma reduzida entrada de divisas. A elevação destas era uma condição importante para viabilizar a industrialização do país que, desde 1930, se vinha consolidando como o "setor chave" da economia brasileira.

Em torno do debate destas questões, duas posições sobressaíram na sociedade: uma defendida por Aguiar (1986), segundo o qual a origem destes problemas estava relacionada à concentração da estrutura fundiária, na forma de latifúndios improdutivos, pelo que se propunha como solução uma Reforma Agrária $^{3}$ para desconcentrar a propriedade da terra. Esta era uma proposta distributivista, que visava aumentar a produtividade agrícola de gêneros alimentícios através da distribuição de terras aos pequenos produtores rurais.

A outra posição baseava-se no atraso técnico da agricultura e não na concentração da terra. Esta vertente via como solução a alteração do padrão tecnológico da agricultura, sem, contudo, mexer na estrutura fundiária. O golpe militar de 1964 elevou ao poder os setores sociais que defendiam esta última posição, contrariando as reformas, nomeadamente a Reforma Agrária. Tratava-se, portanto, de representantes do grande latifúndio que buscaram reorientar a agricultura no Brasil no período ditatorial. A estratégia dominante traçada para o desenvolvimento rural objetivava transformar latifúndios improdutivos em modernas empresas agrícolas. Para viabilizar este objetivo, cabia ao Estado acelerar a modernização tecnológica, visando elevar a produtividade de 
culturas que agregassem valor comercial, destinado, sobretudo, ao mercado internacional. A partir daí, a modernização agrícola constituiu-se na principal diretriz política, como uma nova estratégia de desenvolvimento.

Na década de 1970, já sob os efeitos do "milagre econômico brasileiro", período caracterizado por elevadas taxas anuais de crescimento do produto interno bruto (Filho, 1972: 391), a agricultura atingiu um importante processo de modernização quanto às técnicas de produção. $\mathrm{O}$ uso de trator, insumos, agrotóxicos, sementes selecionadas e medicamentos veterinários passou a ser mais acentuado. É a transformação capitalista da agricultura através da sua modernização. Porém, esta modernização (Graziano Neto, 1994: 26) não é apenas a substituição do burro pelo trator, do estrume pelo adubo químico, da enxada pelo arado. A modernização significa muito mais que isso. Ao mesmo tempo que vai ocorrendo aquele progresso técnico na agricultura, inevitavelmente vai modificando também a organização da produção no que diz respeito às relações sociais e não só às técnicas de produção.

Essa modernização requerida como suporte para o aprofundamento e expansão da sociedade capitalista (Adorno, 1991: 186) avançou sobre as mais diversas atividades, atingindo até o lazer das comunidades rurais (Pessoa, 1999: 51; Barreiro, 1989: 184), como instrumento de inculcação das novas formas, regras e valores condizentes com o novo processo de trabalho.

28 Essas transformações econômicas ocorridas no Brasil, especialmente no setor industrial, refletiram-se no desenvolvimento de novas classes sociais e novas categorias (Oliveira, 1994: 38) de empresários e de trabalhadores, tanto de origem burguesa - comerciantes, banqueiros, industriais, latifundiários - como o seu oposto - o proletariado urbano e rural, formado por operários e trabalhadores destes setores.

Do ponto de vista social e político, historicamente a industrialização capitalista se constituiu na acomodação e articulação dos interesses dos setores tradicionais (as oligarquias agrárias) das classes dominantes (Vita, 1989: 151) com seus setores "modernos" (a burguesia fi nanceira e industrial). Isso não exclui (Cruz, 2002: 27) eventuais escaramuças, como as que ocorreram durante a República Velha no Brasil (1889-1930), período entre a proclamação da república e o início do governo do ditador Getúlio Vargas, em torno de determinadas medidas de política econômica, como, por exemplo, a taxação de produtos manufaturados ou a liberação da importação de matériasprimas utilizadas pela indústria.

30 Entretanto, pesem embora as divergências momentâneas, a marca da modernização brasileira foi a conciliação entre a burguesia comercial urbana e as oligarquias agrárias (Vita, 1989: 152) ${ }^{4}$ que sempre se uniram para o controle da mão-de-obra brasileira, notadamente quanto aos custos das conquistas sociais e do direito à greve. Apesar das mudanças desde o período da abolição da escravatura, em 1888, até a criação do Estatuto do Trabalhador Rural em meados da década de 1960, quando surgiram novas relações de trabalho, tal situação não mudou muito, impedindo a sociedade brasileira de acelerar os avanços sociais necessários.

31 Assim, a modernização no espaço agrário veio interferir cada vez mais na organização interna da produção da agricultura familiar (Wanderley, 1979), através de um modelo forçado, tendencioso e excludente (Martins, 2000), gerando múltiplas consequências de desestabilização das identidades locais que afetaram (Vieira (2001: 96) várias regiões 
produtoras nos Estados nacionais, as quais ficaram debilitadas com a intensidade dos fluxos econômicos globais.

32 No caso do Submédio São Francisco, especificamente o polo de Juazeiro/ Petrolina, as políticas regionais aplicadas implementaram o mesmo modelo de gestão adotado no restante País, tendo como estratégia a política desenvolvimentista levada a cabo pelos sucessivos governos a partir de 1964, que privilegiaram e continuam a privilegiar, na atualidade, os grandes produtores para expansão do grande capital (Oliveira, 1988: 36), visando o mercado internacional de produtos agrícolas.

\section{O local frente a global: análise da agricultura no Submédio São Francisco}

O Vale do Submédio São Francisco não está imune à lógica da globalização e, nestes últimos anos, é a região que melhor representa o Brasil na produção de frutas in-natura nos grandes mercados internacionais. Neste Vale destaca-se, em particular, o polo Juazeiro-Petrolina, o qual é um dos mais importantes produtores nesse segmento, especializando-se na produção de uva, manga e ainda alavancando mais sessenta outros produtos. Mesmo com seu mercado interno, mercados regionais, essa região agrícola está tecida e emaranhada pela atuação de grandes empresas a nível produtivo, que, como referi, envolve um conjunto de mudanças no uso do solo (utilização de máquinas, fertilizantes químicos) e marca a evolução agrícola nestas últimas décadas com o avanço do progresso tecnológico sob a égide do grande capital.

A concentração da atividade produtiva, privilegiada com infraestrutura adequada, e a mão de obra qualificada e barata se apresentam como vantagens competitivas para a instalação de grandes corporações que modificam toda a lógica da organização do território, provocando com isso novos movimentos da população, como consequência da relocação das atividades empresariais.

O impacto dessa reestruturação no sistema produtivo através de políticas liberais afeta, tal como sustenta Castells (1999: 21), todas as pessoas nas redes de relações econômicas, sociais, políticas e ambientais, muito embora em diversos graus, como é o caso da agricultura no Vale do Submédio São Francisco que sofre mudanças sob forte influência dos novos modelos de Gestão e Tecnologias, no âmbito tanto da organização da produção, como do processo das novas relações de trabalho, as quais, por seu turno, não se constituem na base de um determinismo puramente técnico (Bonanno, 1999: 52-53), mas também, influenciadas pela contribuição de uma política imposta pelo Estado, ao longo dos anos, e pelo grande capital.

Este processo significa produzir mais com menor tempo e menos mão de obra, aumentando a produtividade e consequentemente sua competitividade. A cadeia produtiva estende-se para além do mercado nacional, integrando-se nas redes do mercado internacional, coordenadas através de novos atores - o grande produtor, envolvido na produção e distribuição. Tal implica novos modelos de organização econômica e tecnológica, cuja dinâmica não fazia parte da agricultura tradicional de sequeiro e vazante nessa região, que acompanhava o regime do volume das águas do rio São Francisco.

Os atores sociais envolvidos nas atividades produtivas nesse ambiente passam então a adotar as novas exigências de se produzir com qualidade, visando à incorporação de seus 
produtos no circuito das relações globais. Isto implica o controle de tempo, conhecimento, tecnologia e mercado. Os agricultores familiares, por sua vez, tentam seguir o mesmo rumo dos grandes produtores, mas vivem em temporalidades distintas (Franca, 2008: 237), tornando-se um desafio à produção com qualidade, permitindo que sejam incorporados nessa nova tendência de mercado. A dificuldade acontece em decorrência, principalmente, dos modelos organizacionais requeridos pela agricultura, a qual, por sua vez, contempla estratégias para melhor qualidade dos seus produtos e um novo alinhamento, o qual exige uma logística de distribuição mais inovadora e confiável.

Essa nova condição do mercado tem requerido (Cavalcanti, 1999: 165) mercadorias específicas em tempos e formas definidas. Entretanto, a produção de mercadorias para o consumo local e para as dietas regionais, a exemplo da macaxeira e do inhame (Graziano da Silva, 1998: 32), tem sido, relativamente, cada vez menor nesse mercado específico. A racionalização nos processos produtivos e a organização social e tecnológica elegem como meta principal acelerar a produtividade e ampliar as condições de produção de excedentes, num ambiente em que o grande capital impulsiona o Estado, notadamente (Sochazcewsk, 2002: 38), nas políticas de crédito e de estímulos à exportação. Como corolário, este território vem sendo transformado com a introdução dos novos atores sociais, gerando relevantes mudanças na agricultura com grandes impactos econômicos e sociais.

39 Atualmente, a falta de representação da sociedade civil, especificamente dos segmentos mais frágeis, impede que as estruturas produtivas locais (Graziano da Silva et al., 1999: 251) assumam um papel mais relevante para novas formas de (des)regulação que emergem com a globalização. Nesse caso, pela falta de organização por parte da sociedade local ${ }^{5}$, as grandes corporações impõem seus próprios interesses de forma privilegiada, ainda que aparentemente, para se legitimarem na sociedade, se apresentem como indo ao encontro do interesse de todos.

Todavia, ao contrário do que se diz, esta caracterização agrícola não pleiteia o fim da pequena produção, indo ao encontro do que Servolin (1972) já avançara sobre a articulação da grande e pequena exploração. Esta subsiste, e de certo modo se afirma, porém, mais como uma espécie de satélite, produzindo culturas para manutenção dos mercados locais. Conforme destaca Guimarães (1979:76): "convinha ao sistema latifundiário exportador a coexistência com um sistema de produção que se dedicasse à produção de artigos de menor prestígio econômico, cujos lucros menores não lhes eram atrativos."

Os produtos de menor valor comercial são, pois, reservados à pequena produção, imprescindíveis para o crescimento urbano-industrial. Nessa forma de integração econômica, a pequena produção deverá fornecer alimentos à população urbana e matérias-primas à indústria a preço baixo, para não frustrar o processo de desenvolvimento em curso. Nesse contexto, se por um lado, a pequena produção cumpre uma função importante para o processo (Porto e Siqueira, 1994: 81) de acumulação capitalista na sociedade, por outro, a política modernizadora subordina a agricultura familiar por considerá-la funcional ao capitalismo e impõe a sua integração aos capitais industriais, adotando pacotes tecnológicos, para se tornar competitiva.

A melhor performance na execução dessa "missão histórica" é obtida através da estratégia de aumentar o volume de produção, no âmbito da pequena agricultura, pela via da incorporação de inovações técnicas (Duque, 2002). As políticas do Estado que fomentaram essa perspectiva buscam ao mesmo tempo incrementar a produtividade agrícola e, em 
decorrência disso, fortalecer uma camada média de pequenos produtores rurais com "espírito empreendedor", que se diferencia do conjunto dos produtores pobres do campo.

Essa tendência, presente em iniciativas governamentais, não deve, entretanto, ser analisada como uma ação isolada, mas como parte da política nacional para a agricultura, que se articula com interesses externos. De acordo com essa ótica, o produtor familiar, embora se mantenha orientado para o mercado interno, é estimulado a alterar a sua base técnica de uma agricultura tradicional, passando a absorver tecnologias sofisticadas, e direcionar a sua produção aos mercados globais, embora numa posição de subalternidade em relação à grande empresa.

Entretanto, não obstante a influência que as políticas públicas buscam nessa direção, não se pode afirmar que isso leve à formação de uma camada de produtores familiares capitalizados. O que parece mais sensato reconhecer é que o desenvolvimento da agricultura familiar pelo processo de modernização tecnológica pode gerar, em algumas situações, uma melhor remuneração em função da sua produção agrícola. Porém, tais situações não levam, em geral, a mudanças na lógica interna da unidade de produção familiar ou ainda à incorporação de uma racionalidade econômica voltada para a acumulação de capital. A integração desse produtor nesse modelo de desenvolvimento agrícola não significa que ele tenha mudado a lógica da sua unidade de produção, tal como aponta Nazaré Wanderley (1977), ao afirmar que a integração ao mercado

[...] não signifi ca a negação do caráter de subsistência da economia familiar. Esta se define, não pela maior ou menor parcela da produção que é autoconsumida, mas pela natureza da mesma produção. Mesmo que toda esta venha a ser comercializada, a lógica de sua organização permanece orientada para a satisfação das necessidades básicas da agricultura familiar. (Grifo nosso; Wanderley, 1977: 540)

A postura adotada neste estudo sobre a agricultura na região do Submédio São Francisco analisa aspectos dessa natureza, a exemplo da reprodução de relações não especificamente capitalistas, mas subordinadas à dominação do capital. Essa subordinação expressa a forma como ocorre a vinculação, por exemplo, no caso dos agricultores familiares localizados no polo da fruticultura de Juazeiro/Petrolina entre essa produção e a reprodução ampliada do capital. Parte-se do pressuposto de que a formação social brasileira é capitalista e que para entender o caráter específico, no caso da produção nessa região, é necessário, como já foi discorrido, analisar essa formação a partir do processo real histórico de acumulação do capital e do modo como se articula com outros modos de produção não capitalistas como o modo de produção familiar.

A transformação em mercadoria das matérias primas, dos instrumentos de trabalho e dos meios de subsistência criam o mercado interno para o capital. Os agricultores familiares cada vez mais se tornam dependentes do mercado, e ainda que tenham a posse parcial dos meios de produção, esta é mediada pela mercadoria e pelo próprio capital. Entretanto, embora a tendência geral da expansão capitalista seja a de que o capital se aposse e depois destrua as relações de produção não caracterizadas pelo assalariamento, a pequena produção doméstica permanece como forma de produção, mesmo dominada pelo capitalismo. Para Maria de Nazareth Baudel Wanderley,

[...] é precisamente através da mediação do mercado que o capital interfere na organização interna na exploração da produção doméstica, que depende cada vez menos das suas condições naturais. Por outro lado, os mecanismos do mercado capitalista cada vez mais determinam as decisões do montante a ser produzido, a alocação da força de trabalho, a parcela para o autoconsumo e para a 
comercialização e a pauta de produção, entre outras decisões. (Grifo nosso;

Wanderley, 1979: 83)

Esta concepção possibilita-nos compreender os processos sociais - a partir das mudanças e das estratégias desenvolvidas pelo mercado, para atender aos requerimentos da competitividade - e a conversão do grande capital para a pequena produção marcada pelas exigências, bem como os seus impactos nos processos sociais que aqui tem seu lugar.

Nos oito projetos irrigados implantados no polo Juazeiro-Petrolina, segundo informações da Codevasf - Companhia de Desenvolvimento do Vale do São Francisco em 2010, a produção familiar agrícola foi responsável por 265273,71 toneladas de produtos frutícolas, numa área de 13868,80 hectares, gerando uma receita bruta de $\mathrm{R} \$ 92640$ 502,04 . Aparentemente estas cifras podem significar um relativo sucesso dos agricultores familiares instalados no polo Juazeiro-Petrolina, mas escondem uma situação distorcida da realidade desse coletivo.

Tomando-se como exemplo o caso do Projeto de Irrigação Maria Teresa, o qual abriga 540 produtores familiares, a situação não parece ser tão otimista assim. A tabela abaixo pode elucidar esta questão.

\begin{tabular}{|c|c|}
\hline Área Colhida: (hectare) & 2122,58 \\
\hline Produção: (ton) & 39663,33 \\
\hline Valor Bruto $(\mathrm{R} \$)$ & 17471760,20 \\
\hline Custo Variável Médio (R\$) & 8582428,00 \\
\hline Faturamento (R\$) & 8889332,20 \\
\hline N. ${ }^{\circ}$ de Produtores & 540 \\
\hline Ganho Anual médio por Produtor & 16461,72 \\
\hline Ganho Mensal médio por Produtor & 1371,81 \\
\hline
\end{tabular}

No Perímetro de Maria Teresa, em 2009, o total de área colhida foi 2122,58 hectares, com produção de 39 663,33 toneladas gerando um valor bruto de R\$17471 760,20 com um custo de produção variável médio de $\mathrm{R} \$ 8582$ 428,00 obtendo-se assim um faturamento de $\mathrm{R} \$ 8889332,20$ no ano. Se dividirmos este valor pelos 540 agricultores, resultaria uma cifra média de $\mathrm{R} \$ 16492,27$ anuais para cada agricultor, ou seja: $\mathrm{R} \$ 1371,81$ mensais. Isso equivale praticamente a dois salários mínimos. Vale ressaltar que neste cálculo não estão incluídos o custo fixo (oportunidade da terra, administração) e as depreciações (equipamentos, instalações), o capital inicial para a produção do ano seguinte, nem as despesas de manutenção do pequeno produtor e de sua família.

Em comparação a esta realidade, o Quadro 2 abaixo revela a produtividade de um empresário no polo de Petrolina. 


\begin{tabular}{|l|r|r|r|r|r|}
\hline PRODUTO & & UVA & MILHO & GOIABA & TOTAL \\
\hline Área colhida & (A) & 6,00 & 4,00 & 118,00 & 128,00 \\
\hline Volume (T) & (B) & 160,00 & 16,00 & 4720,00 & 4896,00 \\
\hline Valor R\$/ton & (C) & 1250,00 & 2000,00 & 280,00 & \\
\hline Valor bruto & (D) & 200000,00 & 32000,00 & 1321600,00 & 1553600,00 \\
\hline Custo médio Variável & (E) & 90000,00 & 8800,00 & 531000,00 & $\mathbf{6 2 9} 800,00$ \\
\hline Faturamento & F=(D/E) & $\mathbf{1 1 0} 000,00$ & 23000,00 & 790600,00 & 923800,00 \\
\hline Produção Média & G=B/A & $\mathbf{2 6 , 6 7}$ & 4,00 & 40,00 & 70,67 \\
\hline
\end{tabular}

QUADRO 2. GRANDE PRODUTOR

FONTE: CODEVASF/2010

52 Tomando a uva como exemplo, um empresário colheu em 2010, 160 toneladas em seis hectares, que é a média dos lotes dos produtores familiares $(6,4 \mathrm{ha})$, negociando a um valor bruto de $\mathrm{R} \$ 200000,00$. Se se subtrair esse valor pelos custos variáveis, ou seja, pelo que esse produtor investiu que foi no total de $\mathrm{R} \$ 90000,00$, se obtém um faturamento de $\mathrm{R}$ $\$ 110$ 000,00 ao ano, ou seja: R\$ 9167,00 por mês. Outros exemplos podem ser mensurados conforme os dados do Quadro 2 já demonstrado acima, em relação ao milho e à goiaba.

53 A "trama" de relações sociais que se configuram no processo de reestruturação agrícola pelo capital é susceptível de culminar num efeito perverso, em que o crescimento sem emprego é o mais relevante, contribuindo para o aumento da pobreza.

Deste modo, com base no modelo organizativo de desenvolvimento tecnológico ora explanado e na análise da região do Submédio São Francisco, podemos perceber que estamos perante uma configuração de uma modernização conservadora, que mostra (Oliveira, 2003: 32) uma simbiose e uma organicidade, uma unidade de contrários, em que o chamado "moderno" cresce e se alimenta da existência do "atrasado", que resulta em favor de uma minoria privilegiada.

Por outro lado, visualiza-se uma transfiguração social de uma maioria de agricultores familiares, que, inspirados nesse tipo de modelo sob a aparente proteção do Estado, mantêm uma posição fragilizada e dependente enquanto produtores agrícolas, de modo que não têm acesso a esses modelos de gestão organizacional, sendo excluídos das vantagens no novo processo econômico.

\section{Conclusão}

Na medida em que a agricultura familiar receber a mesma atenção que outros setores da economia, por parte do Estado, certamente se tornará sustentável, até porque os investimentos que servem a este setor são, em sua maioria, políticas públicas necessárias ao desenvolvimento local, tais como investimentos em infraestruturas (portos, aeroportos, estradas) e acesso ao crédito. O protagonismo local é o fenômeno pelo qual os agentes locais se reconhecem como sujeitos do próprio destino. Tornam-se atores sociais. Logo, trata-se de um processo de empoderamento de ampliação da esfera pública, de transformação nas relações sociais entre o Estado e a sociedade, entre o Estado e o mercado e entre a sociedade e o próprio mercado. 
57 Estas constatações indicam que as ações de uma política social e pública envolvem não somente o econômico, mas tem uma dimensão própria que resulta da concepção de realidade social como uma totalidade concreta. Abrange também a estrutura cultural que é expressão dos valores e do conhecimento produzido pelos atores sociais em interação e ainda à estrutura política para a qual convergem os processos participativos.

Ainda nesse contexto, relativamente à agricultura dessa região e seu progresso em termos de modernização e processos tecnológicos, trata-se da aplicação de conhecimentos derivados de ciência e das tecnologias. Porém, quanto à agricultura familiar, ela só poderá desenvolver-se no seu aspecto econômico e social, desde que se tenham em conta a transformação dos interesses predominantes dos agricultores familiares que é a produção em comunidade familiar mais voltada para a subsistência do que para a formação de excedentes proporcionando-lhe os instrumentos, recursos e meios de ampliar sua competitividade produtiva e, consequentemente, sua melhoria social. Mas o Estado terá que ir além, investindo em programas de educação e qualificação, em melhorias sanitárias e de saúde e fomentando processos de renda mínima para os agricultores familiares.

É de suma importância que as agências públicas setoriais compreendam que essa categoria só poderá ser entendida, se for analisada à luz de um conhecimento que não subordine o seu desenvolvimento à exclusiva dependência do avanço do progresso tecnicista. Neste sentido, a imagem que se tem da agricultura familiar no Projeto Maria Teresa e demais perímetros públicos de irrigação, como espinha dorsal para melhoria de vida na região Nordeste será tanto mais limitada, quanto menor for o interesse dos órgãos públicos do Estado na resolução dos problemas sociais.

Os recursos da tecnologia e da ciência dos quais se utilizam esses atores institucionais poderiam emprestar à sua atuação um caráter mais impositivo, visto que os meios e os recursos de que se valem os produtores familiares os colocam a distância dos valores, crenças e pautas culturais, no que diz respeito ao modo de ser e de comportar-se.

61 É com base nestes princípios que essas agências públicas poderiam e podem optar por esse segmento maior da população rural. Os valores éticos doutrinários destes princípios devem definir a natureza e os limites das relações dessas agências públicas, de modo a estas não se tornarem substitutivas da iniciativa e livre expressão do homem rural ou marcadas pelo autoritarismo de uma classe dominante e de seus representantes nos parlamentos e nos acordos e barganhas estabelecidas entre ambos, sempre regidas pelas regras de um relacionamento imposto segundo os interesses dos que detêm o poder.

62 A valorização da agricultura familiar é condição para transformação da realidade social em que se encontra atualmente. Neste princípio, parte-se do pressuposto de que esta mudança envolve transformações continuadas e progressivas nas estruturas econômicas, sociais e políticas que se mostram interdependentes e têm como principal agente (pelo menos deveriam) o homem do campo. Em coerência com este princípio ético, cabe a estas agências institucionais e com recurso do Estado, como agente interveniente neste processo de mudança, contribuir para a passagem de uma situação mais favorável, à maioria daqueles ainda sem condições de acesso e controle dos meios e fatores de produção.

63 Como se vê, essa região se por um lado é divulgada pelo seu meteórico desenvolvimento, observa-se por outro lado, no discurso daqueles que a divulgam, que se refuta a extrema condição de desigualdade decorrente de um desenvolvimento contraditório. 


\section{BIBLIOGRAFIA}

ADORNO, Sérgio (1991), “A experiência precoce da punição”, in Martins, José de Souza. O massacre dos inocentes. São Paulo: Hucitec.

AGUIAR, R. Conde (1986), Abrindo o pacote tecnológico: Estado e pesquisa agropecuária no Brasil. São Paulo: Polis.

BARREIRO, Iraíde Marques de F. (1989), Educação rural capitalista. Campinas: Faculdade de Educação da Unicamp.

BENJAMIN, César (1998), A opção brasileira. Rio de Janeiro: Contraponto.

BONANNO, A. A. (1999), “Globalização da economia da sociedade: fordismo e pós-fordismo no setor agroalimentar", in Cavalcanti, Josefa Salete Barbosa (Org). Globalização, trabalho, meio ambiente: Mudanças socioeconômicas em regiões frutícolas para exportação. Recife: Ed. Universitária da UFPE.

CAVALCANTI, Josefa Salete B. (Org.) (1999), Globalização, trabalho, meio ambiente: Mudanças socioeconômicas em regiões frutícolas para exportação. Recife: Ed. Universitária da UFPE.

CARDOSO, R. de O. (2000), “Olhar, ouvir, escrever”, in Trabalho do antropólogo. São Paulo: UNESP.

CASTELLS, Manuel (1999), Sociedade em Rede. 2. ㄹ Ed., Rio de Janeiro, : Editora Paz e Terra.

CHAYANOV, A. V. (1981), "Sobre a teoria dos sistemas econômicos não capitalistas", in Graziano da Silva, J. \& Stolcke, V. A questão agrária. São Paulo: Brasiliense.

CRUZ, Souza Ozelito (2002), Trabalho infantil e ensino fundamental na área do sisal. Dissertação (Mestrado em Educação e Pesquisa) - Universidade do Québec em Chicoutim/ Universidade do Estado da Bahia.

DAHL, R. (1989), Democracy and its Critics. New Haven e Londres: Yale University Press.

DUQUE, Ghislaine (Org.) (2000), Agricultura familiar, meio ambiente e desenvolvimento. Ensaios e pesquisas em sociologia rural. João Pessoa: Editora Universitária, UFPB.

FILHO, Melo Murilo (1972), O milagre brasileiro. Rio de Janeiro: Edições Bloch.

FONTE, E. M. M. (2000), "Políticas públicas e escolhas privadas: interações políticas e econômicas a nível local”, Revista Estudos de Sociologia, Programa de Pós-Graduação em Sociologia, vol. 5 ‥ 2: 31-51, UFPE Recife.

FRANCA, Celso Sales (2008), A imagem do Vale: Reestruturação agrícola e mudança social. Petrolina: PE, Editora Franciscana. Fundação Instituto Brasileiro de Geografi a e Estatística - 2010.

GEERTZ, C. (2000), “Como pensamos hoje: a caminho de uma etnografi a do pensamento moderno", Saber local: Novos ensaios em antropologia interpretativa. Petrópolis: Vozes.

GRAZIANO NETO, F. (1994), Questão agrária e ecologia: Crítica da moderna agricultura. Barcelona. 2." Ed.: Ediciones, Peninsula.

GRAZIANO DA SILVA, José (1999), “Agroindústria e globalização: o caso da laranja no estado de São Paulo", in Cavalcanti, Josefa Salete B. (Org.). Globalização, trabalho, meio ambiente: Mudanças socioeconômicas em regiões frutícolas para exportação. Recife: Ed. Universitária da UFPE. 
GRAZIANO DA SILVA, José (1998), “A globalização da agricultura”, in Miguel Silveira, Sergio L. de O. Vilela (Org.). Globalização e sustentabilidade da agricultura. Jaguariúna: EMBRAPA/ CNPMA.

GUIMARÃES, A. P. A. (1979), Crise agrária. Rio de Janeiro: Paz e Terra.

HAYEK, Friedrich August Von (1990), O caminho da servidão. Rio de Janeiro: Instituto Liberal.

MARTINS, Paulo Henrique (2000), "Imagens ambivalentes da globalização”, Revista Estudos de Sociologia. Programa de Pós-Graduação em Sociologia, vol. 5 n.ำ 2: UFPE Recife.

OLIVEIRA F. (1988), A economia brasileira: Crítica à razão dualista. 6. ed.. Petrópolis: Vozes.

OLIVEIRA, F. de (1987), Elegia para uma re(li)gião: SUDENE, Nordeste. Planejamento e conflito de classes. 5. ed. Rio de Janeiro: Paz e Terra.

OLIVEIRA, Existia Maria Pereira de (1994), o único caminho para mim é aprender a trabalhar. Recife: Ed. Universitária da UFPE.

OLIVEIRA, Francisco de (2003), Crítica à razão dualista. São Paulo: Boitempo.

PESSOA, Jadir Morais (1999), A revanche camponesa. Goiânia: Editora da UFG.

PIORE, Michael J. \& SABEL, Charles (1984), "Possibilities for prosperity”, The Second Industrial Divide. Nova Iorque: Basic Books.

PORTO, M. S. G \& SIQUEIRA, D. A. (1994), "Pequena produção no Brasil: Entre os conceitos teóricos e as categorias empíricas". Cadernos de Sociologia.

SERVOLIN, Claude (1972), "L'absortion de la agriculture dans le mode de production capitaliste", in Y. Tavernier et al. (orgs.). L'Univers politique des paysans. Paris: Collin, 41-105.

SILVA, Manuel Carlos (1998), Resistir e adaptar-se. Constrangimentos e estratégias camponesas no Noroeste de Portugal. Porto: Edições Afrontamento.

SILVA, Manuel Carlos (2005), "Entre o infraestatal e o supraestatal: o Estado-Nação e a democracia em perda", in Silva, M. C. (Org.) Nação e Estado. Porto: Edições Afrontamento, 125-145.

SCHNEIDER, S. A. (2000), Pluriatividade na agricultura familiar. Tese de Doutorado em Sociologia Rural. Porto Alegre: Universidade Federal do Rio Grande do Sul.

SOCHAZCEWSK, Antonio Claudio (2002), "Políticas de crescimento e o futuro do Brasil", in Ricardo Bielschowsky \& Carlos Mussi (Org.), Políticas para a retomada do crescimento: reflexões de economistas brasileiros. Brasília: IPEA; Escritório da CEPAL no Brasil.

VIEIRA, Liszt (2001), Os argonautas da cidadania. Rio de Janeiro: Record.

VITA, Olavo de (1989), Sociologia da sociedade brasileira. São Paulo: Ática.

WANDERLEY, M. e de Nazaré B. (1977), Algumas reflexões sobre o campesinato do Nordeste: conceito e realidade. Ciência e Cultura.

WANDERLEY, M. de Nazaré B. (1979), O camponês: um trabalhador para o capital. São Paulo: Universidade Estadual de Campinas.

YIN, R. K. (2005), Estudo de caso: planejamento e métodos. 3. e ed. Porto Alegre: Bookman.

\section{NOTAS}

1. Não vou neste texto desenvolver a questão da definição do campesinato, a qual ficará para um outro ponto de desenvolvimento da tese, limitando-me a assumir o pressuposto chayanoviano. 
Trata-se aqui de destacar a agricultura familiar, enquanto combinação, numa unidade de produção, de terra, trabalho e família. Por outro lado, analisar-se-á a relação entre este tipo de agricultura e o processo de desenvolvimento das forças produtivas e, em particular, o processo de modernização e integração sócio-econômica global. A literatura brasileira nos anos 90 adotou a expressão Agricultura Familiar quase simultaneamente em duas esferas distintas (cf. Schneider 2000: 30): no campo político por intermédio dos movimentos sociais e do sindicalismo rural e, de outro lado, nos estudos acadêmicos, que passaram a buscar novos referenciais teóricos e analíticos. O Estado legitimou o termo Agricultura Familiar quando instituiu o Programa Nacional de Desenvolvimento da Agricultura Familiar (PRONAF), em 1996, em resposta às pressões do movimento sindical rural.

2. Está composta por oito municípios - quatro pertencentes ao estado da Bahia e quatro ao de Pernambuco - Casa Nova, Curaçá, Juazeiro, Sobradinho e Lagoa Grande, Orocó, Petrolina e Santa Maria da Boa Vista respectivamente, abrigando 686534 habitantes, segundo a última contagem realizada pelo FIBGE, em 2010, envolvidos principalmente nas atividades vinculadas à fruticultura.

3. Deve fazer-se uma distinção entre a questão agrícola e a questão agrária. A agrícola diz respeito aos aspectos ligados às mudanças na produção em si mesma, ou seja; o que se produz, onde se produz e quanto se produz. Já, porém, a agrária está ligada às transformações nas relações de produção - como se produz, de que forma se produz. Enquanto no equacionamento da questão agrícola, as variáveis importantes são as quantidades e os preços dos bens produzidos, na agrária são as maneiras como se organizam o trabalho, a produção, o nível de renda e emprego dos trabalhadores, a produtividade das pessoas ocupadas no campo.

4. A denominação "milagre econômico brasileiro" refere-se a um excepcional crescimento econômico ocorrido durante o regime militar no Brasil, também conhecido pelos oposicionistas como "anos de chumbo", especialmente entre 1969 e 1973, no governo do General Médici. Nesse período, o PIB brasileiro cresceu (Filho, 1972: 391) a uma taxa média acima de $10 \%$ ao ano e a inflação oscilou entre $15 \%$ e $20 \%$ ao ano. Nesse período, paradoxalmente, houve aumento da concentração de renda (a alta nas bolsas de valores brasileiras iniciou-se no final da década de 1960) e da pobreza, instaurou-se um pensamento ufanista de "Brasil potência" e a criação do mote: "Brasil, ame-o ou deixe-o".

5. Ainda que num quadro mais conservador e passadista e sem um cunho de modernização, este bloco de alianças apresenta alguma semelhança na aliança da burguesia compradora com o latifundismo, nomeadamente durante o Estado Novo em Portugal (cf. Silva, 1998).

\section{RESUMOS}

$\mathrm{O}$ artigo pretende discutir como a agricultura no Nordeste brasileiro foi modelada por um discurso ideológico através do Estado na implementação de reformas agrícolas e arranjos produtivos.o perímetro de Irrigação Maria Teresa, localizado no Município de Petrolina - estado de Pernambuco, ocupado por produtores familiares, foi escolhido como estudo de caso. As políticas impostas neste território pelos sucessivos governos privilegiaram grandes produtores em detrimento da agricultura familiar. A crise atual está relacionada não somente com a ausência do Estado, mas, principalmente, com a imposição de modelos organizativos a partir dos anos 70 . Todos os saberes tradicionais foram ignorados, ocorrendo com isso uma "descampesinização" (autonomia, identidade cultural) dessa categoria, em nome de um projeto de modernidade. 
This study aims to discuss how agriculture in Northeast Brazil has been modelled by an ideological discourse through the state in implementing reforms and agricultural production arrangements. The perimeter Irrigation - Maria Teresa, located in Petrolina-PE occupied by smallholders was chosen as a case study. The policies imposed by successive governments in this territory favoured large producers over the family farm. The current crisis is related not only to the absence of the state, but mainly the imposition of organizational models from the 70s. All were ignored traditional knowledge, occurring with this, a "descampesinização"(autonomy, cultural identity) that category on behalf of a project of modernity.

Cette étude a pour but de discuter de la façon dont l'agriculture dans le Nordeste du Brésil a été modélisé par un discours idéologique par l'Etat dans la mise en oeuvre des réformes et des arrangements de production agricole. Le périmètre d'irrigation - Marie-Thérèse, situé dans Petrolina-PE occupé par les petits exploitants a été choisi comme étude de cas. Les politiques imposées par les gouvernements successifs de ce territoire favorisent les grands producteurs au cours de la ferme familiale. La crise actuelle n'est pas seulement liée à l'absence de l'Etat, mais surtout l'imposition de modèles organisationnels des années 70. Tous ont été ignorés connaissances traditionnelles, se produisant avec cela, un "descampesinização » (autonomie, l'identité culturelle) de cette catégorie pour le compte d'un projet de la modernité..

\section{ÍNDICE}

Palavras-chave: agricultura familiar, modernização, globalização, capitalismo

Keywords: globalization capitalism, public policy, Agriculture Family

Mots-clés: mondialisation, le capitalisme, la politique publique, de la famille agricole

\section{AUTOR}

\section{CELSO FRANCA}

Doutorando em Sociologia do Instituto de Ciências Sociais da Universidade do Minho

celsofranca2005@yahoo.com.br 